\title{
LA MADRE FRANCISCA DE VERA (1514-1574), ABADESA DEL CONVENTO DE LA CONCEPCIÓN DE LEBRIJA, Y SU TRATADO DE LA ORACIÓN
}

\author{
Antonio González Polvillo \\ Universidad de Sevilla
}

\section{RESUMEN / ABSTRACT}

Se estudia la vida y espiritualidad de la Abadesa del Convento de la Concepción de Lebrija (Sevilla) doña Francisca de Vera discípula del visionario, profético, milenarista Gómez Camacho inspirador de la sevillana y heterodoxa Congregación de la Granada y maestra y condiscipula al mismo tiempo de Rodrigo Álvarez S.I., confesor de Santa Teresa de Jesús, quien transmitió a Sevilla esta espiritualidad milenarista y cuyos miembros jugarán un papel fundamental para la difusión masiva de la pía creencia en la Inmaculada Concepción de la Virgen María. Francisca de Vera escribió dos tratados sobre la oración que se conservan manuscritos.

We study the life and spirituality of the Abbess of the Convent of the Conception of Lebrija (Sevilla) Doña Francisca de Vera disciple of visionary, prophetic, millenarian Camacho Gomez inspired the Congregation of Seville and Granada unorthodox teacher and classmate and while Rodrigo Alvarez S.I., confessor of St. Teresa of Jesus, who conveyed to Seville this millennial spirituality and whose members play a key role in the mass dissemination of the pious belief in the Immaculate Conception of the Virgin Mary. Francisca de Vera wrote two treatises on prayer manuscripts are preserved. 
El 6 de junio de 1623, se publicó en la catedral de Sevilla un Edicto de Gracia contra los Alumbrados. Fue una decisión tomada por el Inquisidor General don Andrés Pacheco ante la información realizada por la Inquisición sevillana acerca de la multitud de personas que pertenecian a distintos grupos heterodoxos de espiritualidad alumbrada. La decisión había sido tomada por la Suprema previa consulta a los inquisidores sevillanos quienes a su vez habian sido animados por los teólogos dominicos que los auxiliaban. ${ }^{1}$ El Edicto en cuestión ordenaba a todos los que, en su conciencia, se sintieran inculpados por las proposiciones incluidas que en el plazo de treinta dias acudieran al Santo Oficio sevillano para auto denunciarse. Los inquisidores y sus consultores habian distinguido en sus investigaciones a tres grupos de estos alumbrados: uno de ellos fue la misteriosa y hermética Congregación de la Granada. ${ }^{2}$

Los teólogos dominicos que actuaron de consultores inquisitoriales tuvieron una especial aversión a la Congregación de la Granada, ya que sus miembros habían protagonizado unos años antes un extraordinario movimiento que trasladó desde las escuelas teológicas a la masa popular sevillana, y desde Sevilla se hizo universal, el delicado asunto de la Inmaculada Concepción de la Virgen respecto del cual los dominicos se habian mostrado tradicionalmente contrarios, por lo que este Edicto tiene mucho de expresión de una venganza dominica producto de la humillación que la Orden de Predicadores habia sufrido en Sevilla por parte de prácticamente toda la población de la ciudad que los habian vituperado por esta contradicción. ${ }^{3}$

1 HUERGA, Álvaro. (O.P.), Historia de los Alumbrados. IV. Los alumbrados de Sevilla (1605-1630). Madrid, FUE, 1988, p. 182.

2 Sobre la Congregación de la Granada pueden verse nuestros siguientes trabajos: La Congregación de la Granada, el inmaculismo sevillano y los retratos realizados por Francisco Pacheco de tres de sus principales protagonistas: Miguel Cid, Bernardo de Toro y Mateo Vázquez de Leca, en "Atrio. Revista de Historia del Arte", (2010), pp. 47-72; Inquisidores, dominicos y alumbrados de la Congregación de la Granada en la génesis del inmaculismo sevillano del siglo XVII, en "Anuario de Historia de la Iglesia Andaluza”, IV, (2011), pp. 117-142; El jesuita y confesor de Santa Teresa de Jesús Rodrigo Álvarez: características y genealogía de su espiritualidad, en "Hispania Sacra", LXIV, 129 (enero-junio 2012), pp. 141-186; El acervo cultural de un milenarista de la Sevilla Barroca: la biblioteca del doctor Bernardo de Toro, en "Anuario de Historia de la Iglesia Andaluza", V, (2012), pp. 279-315.

3 GONZÁlEZ POLVILLO, Antonio, Inquisidores, dominicos y alumbrados, p. 118 


\section{LA CONGREGACIÓN DE LA GRANADA}

La historia de la Congregación de la Granada quedó definida por uno de estos consultores de la Inquisición sevillana, el dominico fray Domingo Farfán quien en 1626 redactó un memorial acerca de la misma. ${ }^{4}$ Para Farfán, la sevillana Congregación de la Granada, tuvo creencias peregrinas objetivadas en ceremonias y observancias de una nueva religión, de tal manera que, para el consultor inquisitorial, se convertía en una máquina monstruosa capaz de poner en peligro la unidad de la Iglesia a la que pretendian reformar. Entre sus doctrinas se encontraban las siguientes:

a) Siempre había de haber y nunca habria de faltar un cabeza de la Congregación hasta el fin del mundo.

b) El cabeza tendría el espíritu de Jesucristo, un espíritu que sería heredado por sus sucesores hasta el fin del mundo.

c) La Congregación tenía un secreto singularísimo que solo conocía el cabeza pero que éste comunica a los que llamaban del particular espiritu, que tenían el espíritu de los Apóstoles y que juraban no comunicarlo a nadie a excepción del Papa, el rey, el obispo o el Santo Oficio.

d) Tenían los congregados por particular y cierta observancia y como profecía que, en definiéndose como dogma de fe el punto de la Concepción de Nuestra Señora, habían de reformar la Iglesia los congregados de la dicha Congregación.

e) Que en el fin del mundo y en el tiempo del Anticristo, los que llegasen vivos de esta Congregación a ese tiempo habían de morir mártires por la confesión de la fe y del Evangelio de Cristo. Al llegar este momento, los que ya hubieren muerto de la Congregación en aquel tiempo del Anticristo, habian de resucitar para pelear contra el dicho Anticristo.

4 A.H.N. Inquisición, Leg. 2963/1. Domingo Farfán, Informe calificador sobre la Congregación de la Granada. 
Fray Domingo explicita que la Congregación había tenido como fundador a un cerrajero jerezano, Gómez Camacho (1541-1553), a quien sucedió tras su muerte el clérigo lebrijano, y después miembro de la Compañía de Jesús, además de confesor en Sevilla de Santa Teresa de Jesús, Rodrigo Álvarez (1553-1587), que había sido discípulo espiritual de Camacho y de la Abadesa del convento de la Inmaculada Concepción de su propia villa, Lebrija, doña Francisca de Vera; a este sucedió como cabeza de la Congregación el clérigo sevillano Hernando de Mata (1587-1612), discípulo predilecto del jesuita y predicador catedralicio en el púlpito de junto a la capilla de la Granada, al que sucedió el también clérigo sevillano Bernardo de Toro (1612-1643), ultimo cabeza de la Congregación quien, cuando se inició la persecución, se hallaba desde 1616 en Roma enviado por Felipe III como agente de la causa de la definición de la Inmaculada Concepción y que fue votado a prisión por la Inquisición sevillana tras el citado Edicto, si bien jamás volvería de Roma para ser juzgado. ${ }^{5}$

\section{EL FUNDADOR DE LA CONGREGACIÓN DE LA GRANADA GÓMEZ CAMACHO: EL PROFETA DE LA PARUSÍA}

Según un memorial que el último cabeza de la Congregación de la Granada, el doctor Bernardo de Toro, entregó en noviembre de 1615 en su propia mano a Felipe III, para fundamentar la importancia de insistir ante Roma en la definición del dogma de la Inmaculada, y en el que se expone un compendio de la historia de la Congregación, Gómez Camacho había entrado en 1541 en contacto con una monja del Convento de Mínimas de Jerez llamada Marta de San Andrés quien le habría enseñado la virtud conformando así su personalísima espiritualidad. ${ }^{6}$

GONZÁLEZ POLVILLO, Antonio, Inquisidores, dominicos y alumbrados, ob. cit., pp. $132-136$

6 JESÚS MARÍA, Pedro de, Vida, virtudes y dones soberanos del venerable y apostólico padre Hernando de Mata..., Málaga, 1663, fol. 3v. El biógrafo de Hernando de Mata, cabeza de la Congregación de la Granada tras suceder a Rodrigo Álvarez, afirma que este memorial de Toro: trata la espiritual genealogía, que trae su origen y principio desde S. Francisco de Paula, hasta el Padre Bernardo de Toro, Autor del mismo memorial. 
Las doctrinas de la Congregación de la Granada que la Inquisición sevillana había aislado en su investigación son claramente milenaristas y apocalipticas: exégesis del Apocalipsis de Juan; vuelta a una Iglesia prístina; reforma de la Iglesia; lucha con el Anticristo; Segunda Venida de Cristo o Parusía; fijación de la fecha o momento de esa Parusía con la definición del dogma inmaculista; Reino del Milenio y Juicio Final. Estas doctrinas las había aprendido Gómez Camacho de la monja mínima jerezana Marta de San Andrés y se encargará de transmitirlas a sus discipulos. Unas doctrinas que provienen, en un primer instante, del propio San Francisco de Paula expresadas por el santo calabrés en sus famosas cartas al aragonés, estante en Nápoles, Simón de la Limena a quien habia profetizado que tendria descendencia, que además sería hijo espiritual del propio Paula, que llegaría a capitanear a una gente santa que destacarían en armas y en letras, una última orden religiosa, denominada la de los Santos Crucíferos quienes aniquilarían las herejías y tiranías del mundo, reformarian la Iglesia y lucharian contra el Anticristo, tras la cual se produciria la Parusía. ${ }^{7}$

\section{JOAQUÍN DE FIORE (1135-1202) Y LA ACELERACIÓN DE LA HISTORIA}

Lo extraordinario de todo esto es la presencia de estas ideas milenaristas conservadas con gran mimo hasta el pleno Barroco sevillano. ${ }^{8}$ Sin embargo, el origen de estas creencias apocalipticas no es desde luego San Francisco de Paula (1416-1507) sino otro calabrés que vivió tres siglos antes: el abad Joaquín de Fiore (1135-1202); por consiguiente, las ideas de la Congregación de la

GONZÁLEZ POLVILLO, Antonio, El jesuita y confesor, ob. cit. pp. 143-148.

En el extenso artículo, ya citado, de Hispania Sacra, establecemos la genealogía espiritual de la Congregación de la Granada, tomando como punto de partida la espiritualidad de san Francisco de Paula, tal como afirmaba el Memorial entregado por Bernardo de Toro a Felipe III y cuyas afirmaciones confirmaba el biógrafo de Hernando de Mata. De cualquier forma, y como en el citado artículo anunciábamos, ultimamos una monografia de más amplio calado sobre la Congregación, sus personajes, sus creencias y sus raíces espirituales, escatológicas y apocalipticas. 
Granada están inmersas en una herencia medieval. ${ }^{9}$ La irrupción de Fiore en el panorama del cristianismo europeo medieval significó un punto de inflexión en las esperanzas de la sociedad, de manera que, a pesar de la prohibición que el propio Cristo había hecho de predecir el día o la hora de la Parusía y del agnosticismo que demostró San Agustín contra todo intento de determinar o fijar el momento del fin de las Cosas Últimas, ejerciendo así una poderosa influencia antimilenarista en la sociedad cristiana, con la llegada de Fiore a fines del siglo XII todo comenzará a cambiar, con él se instalará una apocalíptica optimista, exponiendo en su Expositio in Apocalipsim una pauta trinitaria progresiva de la historia que alcanzaria un nuevo climax espiritual dentro de la propia historia humana sin tener que esperar el Juicio Final. ${ }^{10}$ Es en esta concepción de la historia de Fiore y sus seguidores renacentistas, donde encontramos las ya conocidas doctrinas escatológicas: las Cosas Últimas con la presencia del Anticristo cuya derrota conduciría de forma inmediata al Juicio Final; la existencia de una última orden religiosa, los viri spirituales, los nuevos hombres espirituales, es decir, la Congregación de la Granada, que renovarían la vida apostólica previa a la manifestación del Anticristo. Por tanto, lo que tenemos en estos miembros de la Congregación de la Granada, es un grupo milenarista, visionario, apocalíptico, escatológico y reformista que pretenden una aceleración de la Historia -insertos por consiguiente en una vieja tradición europea- y que aportan una novedad extraordinaria: fijar el grandioso acto de la Parusía en el momento de la definición del dogma de la Inmaculada Concepción, de ahí la intensa labor realizada en Roma para conseguir esta definición por el último cabeza de la Congregación, el doctor Bernardo de Toro. ${ }^{11}$

9 REEVES, Marjorie, The Medieval Heritage, en "Prophetic Rome in the high renaissance period", Oxford, Clarendon-Press, pp. 3-23

10 Mc GINN, Bernard, El fin del mundo y el comienzo de la cristiandad, México, FCE, 1998, p. 104.

11 Sobre este interesante personaje puede verse, para su papel en la Congregación de la Granada, a GONZÁLEZ POLVILLO, Antonio, Inquisidores, dominicos y alumbrados, ob. cit., pp. 117-142; y para un estudio de su biblioteca a GONZÁLEZ POLVILLO, Antonio, El acervo cultural de un milenarista, ob. cit., pp. 279-315. 


\section{LA ABADESA DEL CONVENTO DE LA CONCEPCIÓN DE LE- BRIJA: DOÑA FRANCISCA DE VERA (1514-1574)}

Si el fundador de la Congregación fue Gómez Camacho, será Rodrigo Álvarez quien traslade estas creencias desde el eje JerezLebrija a Sevilla. Ya hemos referido cómo este clérigo lebrijano fue discipulo, y sucesor, de Gómez Camacho pero también de la Abadesa del convento concepcionista de Lebrija doña Francisca de Vera, convento en el que Álvarez, antes de su traslado a Sevilla, fue confesor. ${ }^{12}$ Es ahora cuando nos detenemos en el estudio de la vida y espiritualidad de esta monja, así como en observar su papel en esta cadena genealógica de espiritualidad tan singular. La vida de la Madre Francisca de Vera se conserva en dos manuscritos inéditos: uno conservado en una biblioteca particular sevillana, al que suponemos anterior a 1646; y, otro, el conservado en el propio convento de la Concepción de Lebrija fechado en $1663 .{ }^{13}$

\subsection{Biografia minima}

Doña Francisca de Vera (1512-1574) nació en Jerez y fue llevada por sus padres al convento de Lebrija con sólo dos años. Desde los tres años dio muestras de sus virtudes y de su calidad de escogida del Señor quien le dio como maestra a su propia Madre la Virgen: de quien deprendió las virtudes y oraçión que desde tan tiernos años exersitó. ${ }^{14}$ En general, el libro de la Vida de Francisca de Vera hace alusión a todos los tópicos que, generalmente, se les suele adjudicar a aquellas monjas que habian vivido y muerto en olor de santidad. Llena de virtudes: humildad, pobreza, oración,

12 GONZÁLEZ POLVILLO, Antonio, El jesuita y confesor, ob. cit., pp. 62-63.

13 En la actualidad nos encontramos preparando una edición contrastada de ambos manuscritos.

14 Libro de la vida y Milagros de nra. santa madre Doña fransisca de Uera digníssima abb. ${ }^{a}$ de este Religioso conu. ${ }^{\text {to }}$ de la inmaculada consepçion de nra. S. ${ }^{\text {ra }}$ de la villa de Lebrixa; sacada de diuersos escritos que se hallaron en el archiuo del mesmo conu. ${ }^{\text {to }}$ y de testigos de vista, como fueron algunas religiosas que la uieron y trataron. Por una indigna monga de su mesmo conu. ${ }^{\text {to }}$, Año de 1663, con un traslado de la informaçión de sus milagros que se hiso con miçión del ordinario por el Yllm. ${ }^{\circ} \mathrm{S} .{ }^{r}$ cardenal de Roma Don Rodrigo de Castro, Arçobispo de Sevilla, firmada del notario y testigos, p. 3. Archivo del Convento de la Inmaculada Concepción de Lebrija. 
caridad, buen gobierno, santa obediencia a sus prelados. Asimismo se le adjudica los típicos dones, algunos de ellos sobrenaturales: lágrimas, consejo, profecía, hechos extraordinarios ocurridos a su muerte y tras ella. Al desarrollo de estas virtudes y dones se les dedican sendos capítulos del libro manuscrito ejemplificándolos.

Francisca de Vera fue elegida abadesa en 1542, con treinta años de edad, cargo que ostentó durante otros treinta años y murió siendo abadesa el 21 de diciembre de 1574, a los 62 años. ${ }^{15}$

\subsection{La madre Francisca de Vera y su relación con el matrimonio visionario Gómez Camacho-Catalina Ximénez}

Sin embargo, la importancia de Francisca de Vera está, a mi juicio, en su inserción en la cadena genealógica de ese grupo espiritual, fundado inicialmente en el eje Jerez-Lebrija por el cerrajero Gómez Camacho y su mujer Catalina Ximénez, que va a trasladar a Sevilla su discípulo Rodrigo Álvarez (+1587), convirtiéndose así en un triángulo espiritual interconectado, a través de la escritura epistolar, formado por miembros estantes en Jerez-Lebrija-Sevilla y que los investigadores inquisitoriales en 1623 denominaron Congregación de la Granada.

La inclinación a la oración mental de la Abadesa así como su relación espiritual desde la misma niñez, por medio de visiones, con la Virgen y el propio Cristo, preparaban el terreno para establecer contactos con aquellas personas dadas a este tipo de espiritualidad. No cabe duda de que una de ellas fue el discípulo de la monja mínima jerezana Marta de San Andrés: Gómez Camacho. No sabemos muy bien cuándo se establece esta relación entre Francisca de Vera y el matrimonio visionario-milenarista, pero tuvo que ser desde los inicios de la labor proselitista-evangélica de Camacho, establecida por el Memorial de Bernardo de Toro en Jerez en torno a 1541. En efecto, Francisca de Vera fue elegida Abadesa en 1542 y ya antes de esa fecha conocemos la relación entre ambos. Así, sabemos que un día estando Vera en oración le fue comunicado por el Señor: que

15 Libro de la vida, ob. cit., p. 43 
era su voluntad criase al niño Jesús. Vera no entendió muy bien este mensaje pues ella siempre había considerado en su alma a Jesús como un hombre en su Pasión; sin embargo, afirma la biógrafa: $\mathrm{Su}$ Majestad por medio de un alma santa le declaró que en esto le desía quería le sirviese en criar las nueuas planticas de la religión siendo maestra de nouiçias. No cabe duda, sobre todo si nos atenemos a otros hechos similares posteriores, que este alma santa que ejerce de hermeneuta divina o fue Camacho o, más bien, su visionaria mujer, la denominada por todo el convento Madre Catalina Ximénez.

Otro episodio, de los varios recogidos en el libro en los que se establece esta relación, quizás el más importante, también tuvo lugar cuando aún no era Abadesa en la denominada conversión de su propia hermana, doña Ana de Vera, monja en el mismo convento pero del que intentó salir para contraer matrimonio, y en el que la biógrafa da cuenta de la vida de Gómez Camacho, auténtico protagonista de esta conversión. No podemos extendernos aquí, pero la biógrafa narra cómo Camacho, acompañado, entre otros, de Rodrigo Álvarez, acudió al convento y transmutada su personalidad en la del mismo Dios terminó por convencer a doña Ana quien quedó "convertida" en el convento. ${ }^{16}$

\subsection{La Cofradia de las Santas Misericordias}

Francisca de Vera, como Abadesa, no parece que fuera muy amiga de la asistencia de sus monjas al libratorio, a no ser que fuese con padres o familiares cercanos. Solía decir que era mejor hablar con Dios que no de Dios, a pesar de ello, organizó dentro del convento un grupo selecto de cuatro monjas: María de Valer; Ana Rodriguez del Ojo; Luisa de la Cruz y Beatriz de la Magdalena, a las que se añadieron los confesores, que se denominó: Cofradía de las Santas Misericordias. Estas misericordias hacen alusión a los hechos extraordinarios que ocurrian en el convento, y fuera de él. La biógrafa alude a estas misericordias que Dios tenía con Francisca de Vera en forma de continuos y singularísimos favores que llovian sobre su s. ${ }^{\text {ta }}$ alma como la espesura y continuación de

16 GONZÁleZ POLVILlO, Antonio, El jesuita y confesor, ob. cit., pp. 156-158. 
qu. ${ }^{\text {do }}$ del çielo cae copos de nieue sobre los altos montes que los cubre su albura, asi la vido la $m .{ }^{e}$ Cathalina Ximénes s. ${ }^{\text {ta }}$ criatura mujer del p. ${ }^{e}$ Gómes Camacho. ${ }^{17}$

La monja biógrafa llega a narrar cómo tuvo lugar esta visión: ${ }^{18}$

Estava esta sierva de Dios en su oraçión y mi s. ${ }^{\text {ta }} m .^{e}$ en su conu. ${ }^{\text {to }}$ en su s. ${ }^{\text {to }}$ exersiçio postrada a los pies de la ymajen de nro $S .{ }^{r}$ Jesuchristo $y$ vidola en su espiritu la s. ${ }^{\text {ta }}$ Cathalina Ximénes que se deriuauan del $s .{ }^{\text {to }}$ crusifijo infinitas misericordias a modo de copos de nieue sobre el alma de mi $S{ }^{\text {ta }}$ m. $^{e}$ con que la dejaua llena de dulsura y misericordias.

Sin embargo, la Cofradia de las Santas Misericordias se constituía fundamentalmente para realizar: ${ }^{19}$

en oras señaladas $p .{ }^{a}$ pláticas y oír a nra s. ${ }^{\text {ta }}$ m..$^{e}$ referir la grandeza de las obras de Dios en sus ss. ${ }^{\text {mas }}$ misericordias particularmente las que obraua en el siervo de Dios el P. ${ }^{e}$ Gómes Camacho y su $S .^{\text {ta }}$ mujer la m.e Cathalina Ximénes que uiuían en la siudad de Xeres como queda dicho y en este conu. ${ }^{\text {to }}$ tenía mi s. ${ }^{\text {ta }}$ m..$^{e} D{ }^{a}$ Fran..$^{c a}$ de Vera noticias por la communicaçión de sus espiritus de las misericordias que Dios obraua en aquel S. ${ }^{\text {to }}$ varón.

\subsection{Francisca de Vera y la cultura escrita: E1 Tratado de Oración}

Tal como la santa abadesa había declarado a sus confesores, su maestra de virtud y oración fue, desde los tres años, la mismísima Virgen de tal manera que: ${ }^{20}$

fue mayor en virtud que en edad siendo aun imperfecto en el pronunçiar era maestra de oraçión y no es mucho pues tal maestra le enseñó y llegado el tiempo que oya leer libros de oraçión y espirituales se demudaua su rostro y el color rosado en sus mejillas y ojos jusgando sauian las presentes lo que pasaua en su interior y le auia enseñado la uirjen ss. ${ }^{\text {ma }}$ y le auian escrito en aquellos libros, tanta era su humilldad que se temía se supiese favor semejante.

${ }_{17}$ Libro de la vida, ob. cit., p.18.

18 Ibídem, pp. 18-19

19 Ibídem, pp. 64-65.

20 Ibídem, p. 4. 
Siguiendo el tópico acostumbrado, la biógrafa de la Madre Vera afirma que, a pesar de no haber sido enseñada por maestros de artes, estuvo dotada de una gran sabiduria: conoció la gramática, fue excelente cantante y organista asi como contadora conventual, de ahí que durante muchos años llevase la contabilidad de la comunidad. Además, Vera era muy continua en el coro y en el oficio divino, siempre llevaba un breviario, cuando leía la lección en las contemplaciones lo hacía con tanta devoción que atraía a los que escuchaban y encendía con fruición sus corazones, tal era así que: los sábados que después de dicha salue y completas en el coro alto leía en la contemplación venía muchissima gente a la iglesia solo a oírle la lección, tanto era el feruor y graçia con que disponia esta lectura que la seguian como a un afamado predicador. ${ }^{21}$

En el libro se recogen algunos escritos de la monja enviados sobre todo a su confesor, pero al mismo tiempo hijo espiritual, el capellán mayor del convento, vicario y, además, visitador de conventos del arzobispado, el doctor Bartolomé García del Ojo. Destacan dos pequeños trataditos: el Soliloquium Divinum, escrito cuando su hijo espiritual pensaba retirarse al yermo, que la biógrafa incluirá al final del libro y del que la misma realiza el siguiente juicio crítico: ${ }^{22}$

tan lleno de doctrina y de la perfecta caridad de amor de Dios y del próximo con lugares de la sagrada escritura que el más auentajado teólogo tendría mucho de qué admirarse si saue que una criatura desde tan tiernos años en este conuento sin estudio ni enseñanza humana se remontara tanto y con fundamentos tan llenos de ciencia diuina.

La citada biógrafa incluye también cuatro cartas de la Abadesa dirigida a su confesor-hijo espiritual, el citado doctor Bartolomé García del Ojo. Curiosamente, la compiladora advierte de la dificultad de comprensión del lenguaje de intercomunicación de ambos, por lo que para inteligencia de las cartas, incluia una relación de mercedes que el propio Dios había concedido al citado doctor que, al decir de la biógrafa, se encontraban autógrafas

21 Libro de la vida, ob. cit., pp. 59-60.

22 Ibídem, p. 190. 
de la propia Abadesa a manera de avisos para el dicho padre. $\mathrm{Ni}$ que decir tiene que en el desarrollo de estos Avisos se incluyen alusiones visionarias tan propias de la praxis vital conventual de esta monja.

Por último, se incluye igualmente un segundo tratadito de Francisca de Vera, esta vez alusivo a la importancia de la oración y que la Abadesa dedica a sus novicias y monjas. Se trata del Tratado de la Oración que ahora editamos y que comienza con el Salmo 55,7: Quién me dará alas como de paloma y bolaré y descansaré. Al mismo tiempo que se incluye en el Libro de la vida de la Abadesa, este Tratado de la Oración, en su versión original de la propia mano de la madre Francisca de Vera, se conserva en el convento lebrijano en un pequeño cuaderno que a continuación transcribimos $\mathrm{y}$ analizamos. ${ }^{23}$

\title{
5. EL TRATADO DE LA ORACIÓN Y CONSEJOS A LAS NOVICIAS Y MONJAS
}

\author{
[TRATADO DE LA ORACIÓN]. ${ }^{24}$
}

IHS. Quién me dará alas como de paloma y bolaré y descansaré. ${ }^{25}$ Es tan alto este buelo del alma a dios por la or[aci]o[n]. q. lo pedía

${ }^{23}$ El traslado puede verse en Libro de la vida, ob. cit., cap. XXXVI en que se pone un tratadito que hiso nra s. ${ }^{\text {ta }}$ m. $^{e} D .^{a}$ fran. ${ }^{\text {ca }}$ de uera en que trata de quán importante es la oraçión, pp. 177-193. El Tratado de la Oración, original de la Abadesa, se conserva en un pequeño cuaderno, en $12^{\circ}$, de 18 páginas no foliadas más las cubiertas de papel, que aquí editamos.

24 En el verso de la cubierta del manuscrito y escrito por una mano posterior: Este cuadernito es de nra. m..$^{e}$ Doña fran..$^{c a}$ de vera y su mesma letra. Se trata de un pequeño cuaderno conservado en el Convento de la Inmaculada Concepción de Lebrija de la propia letra de la Abadesa Francisca de Vera. Agradecemos a la Madre Abadesa Sor María José Sánchez su generosidad al permitirnos fotografiarlo para su estudio y publicación.

25 Salmo 55, 7. Si el tratado de Francisca de Vera versa sobre la oración es consecuente que lo comience con este Salmo en el que David, agobiado por la rebelión de su hijo Absalón, ora a Dios pidiendo una demostración de su favor divino al mismo tiempo que expone su tristeza y sus temores. David elige alas de paloma en lugar de halcón, no pretende abalanzarse sobre su presa sino volar a la altura que lo hacen las palomas para buscar refugio en el pecho divino. 
davit al señor co[n]. grande ynstançia y en ottra parte dize: los que esperan en el señor mudarán la fortaleza tomarán alas de aguyla bolarán y no desfallecerán. ${ }^{26}$

El aguila desfalleçe por la falta del mantenim. ${ }^{\circ}$ por q. se le encorva el pico y el remedio q. toma es dar en vna piedra fasta que le quiebra y come y toma esfuerço y buela muy alto hasta q. con el calor del sol desecha las plumas vyejas y toma las nuebas.

Asi el a[n]i[m]a. q. a gustado el manjar el ma[n]jar q. el señor da en la or[aci]o[n]. co[n]. que el a[n]i[m]a. cobra alas pa[ra]. bolar co[n]. el entendim[ient]. ${ }^{\circ}$ y bolu[n]tad y llegar a su descanso q. // como pedía dabit biene a enbejeçerse por el trato de las cosas de la $\mathrm{t}$ [ie]rra. y conbersaçiones q. la entibian va p[er]diendo el gusto de la or[aci]o[n]. y vyene a p[er]der el exerçiçio de suerte que pierde el manjar y byene a desfalleçer en la co[m]municaçión del señor y a estar abatida comyendo t[ie]rra. y manjares della como dezía davit q. se secó como el heno y se olvydó de comer su pan ${ }^{27}$. Pues la q. se esfuerça a tomar el remedio de dar en la piedra q. es Xpo. nro. Señor muchos golpes llamando por la or[aci]o[n]. quiebra aquella dureza

${ }^{26}$ Francisca de Vera alude inmediatamente a las alas de águila de Is, 40, 31. Esta alusión es muy interesante, dentro del naturalismo franciscano-monjil de su tratado, tiene connotaciones con la mística carmelitana. En la espiritualidad más o menos "alumbrada" sevillana, de la que Vera es un eslabón principal, la Noche oscura de San Juan de la Cruz fue el libro de cabecera de sus adeptos; ver HUERGA, Álvaro (O.P.), Historia de los Alumbrados, ob. cit., pp. 238-260. En él San Juan también glosa el tema del águila de Isaías, en el que el vuelo del águila hacia el sol presenta connotaciones con el vuelo del espíritu que San Juan de la Cruz utiliza para describir arrobos, éxtasis o raptos del espíritu a Dios. Alude a él en el sexto grado de amor: El sexto grado hace correr al alma ligeramente a Dios y dar muchos toques en él, y sin desfallecer corre por la esperanza, que aqui el amor (que) la ha fortificado la hace volar ligero. En el cual grado también dice el profeta Isaías: 'Los santos que esperan en Dios mudarán la fortaleza, tomarán alas como de águila y volarán y no desfallecerán', como hacian en el grado quinto". DE LA CRUZ, Juan, Obras Completas. Madrid: BAC, 1991, p. 572. Para Vera el alma, la paloma o el águila, gracias a sus alas, el entendimiento y la voluntad, puede elevar ese vuelo espiritual hacia Dios. Sin embargo, el águila para alimentarse debe tener a punto su pico, que tiene tendencia al encorvamiento, tocando en la piedra; así, el alma debe renovar el alimento divino tocando en la piedra de Jesucristo por medio de la oración.

27 Salmo 102, 5: trillado como el heno, mi corazón se seca, y me olvido de comer mi pan. 
del pico y toma el mantenim[ient]. ${ }^{\circ}$ el qual le haze tomar esfuerço y mudar la fortaleza. El a[n]i[m]a. q. se llega al señor muda la fortaleza. La q. era soberbia mudase en humylde. La mormuradora en silençio. Finalmente cobra alas de aguyla mudando la flaqueza q. antes tenía por el trato y conversaçión de acá en fortaleza con la or[aci]o[n]. y co[m]munycaçión con dios.

// Y con esto se aserca y llegandose como el aguila al divino sol de gustiçia, se renueba y purifica de modo, que vivificada de nuebo y illustrada con los rayos de este divino sol, se cumple en ella, lo que dize david: accedicte ad eum et illuminamini, ${ }^{28}$ y siendo illuminada deste divino señor biene a tanto cognosimiento de su divina majestad y de sí mesma, que como con nuebas alas renobadas al fuego y luz del divino sol de justisia le asen bolar y no desfalleçer y este conoçerse la criatura haze ensanchar el vaso evacuandolo de nosotros pa[ra]. q. el señor lo hincha de sy.Ase de myrar mucho en estas dos alas co[n]. q. abemos de bolar q. son entendim[ient]..$^{\circ}$ y bolu[n]tad por q. esta voluntad es la reyna ciega y va por donde le adiestran y el entendim[ient]. ${ }^{\circ}$ es el paje de hacha, como quando va vna señora y llebale el paje vna antorcha y des q. ella entra en la cámara quedase fuera y asi se a de notar q. el entendim[ient]. ${ }^{\circ}$ a de enseñar $\mathrm{p} .^{\circ}$ des[de] q. la volu[n]tad comyença dexalla q. entre y ame q. es su ofiçio porq. el solo entender no es el q.e haze la obra syno el mucho amar y tanbién des[de]q. el a[n]i[m]a. entiende las merçedes y benefiçios del señor // IHS. la conmunycaçión que tienen co[n]. él no a de ser themerosa syno hazer como ester posponer los themores q. ally le pusyeren y confiarse y no dexar de entrar a pedir ${ }^{29}$ y asi

28 Salmo 34-6: Accedite ad eum, et illuminamini: et facies vestrae non confundentur. Los que miraron a él fueron alumbrados y sus rostros no fueron avergonzados.

29 Vera alude a un asunto clave en la tradición de la filosofia metafísica occidental, se trata de la cuestión del voluntarismo y, por ello, de la libertad, del libero o servo arbitrio. La abadesa de Lebrija es voluntarista pero, como Tomás de Aquino y toda la escolástica, afirma el oscurantismo de la voluntad, a la que Vera llama la "Reina ciega", una voluntad que es también amor, un amor voluntarista que, en principio, no puede amar si no conoce, debe estar auxiliado del intelecto, del entendimiento, con lo que ya estarían formadas las "dos alas co[n]. q. abemos de bolar": entendimiento y voluntad. La voluntad es por tanto ciega "y va por donde le adiestran", un adiestramiento que debe ser llevado a cabo por el entendimiento que Vera, siguiendo la tradición de la filosofia escolástica, compara con la antorcha del paje que debe iluminar, enseñar, el camino a esa señora-alma: "el 
hizo ester queria pedir al Rey la vyda de su pueblo estava la suya en condiçión por lo q. el Rey avía mandado determinó de adornarse y con dos donzellas aconpañada entrar al Rey $\mathrm{p}[\mathrm{er}] .^{\circ}$ no dexó de desmayarse. ${ }^{30}$

Asy el a[n]i[m]a. esposa del señor todo poderoso ase de esforçar y p[er]der todo themor aunque le parezca q. por su gran mag[estad].

entendim[ient.$^{\circ}$ es el paje de hacha, como quando va vna señora y llebale el paje vna antorcha y des[de] q. ella entra en la cámara quedase fuera”. Ahora bien, una vez enseñado, "des[de] q. la volu[n]tad comyença", el entendimiento debe dejar a la señora-alma "q. entre y ame q. es su ofiçio". Es la voluntad, que ya no es ciega porque está iluminada, quien elige, el entendimiento solo ilumina, no decide. Francisca de Vera apuesta por un voluntarismo intelectualista de impronta escolástica:

porq. el solo entender no es el q.e haze la obra syno el mucho amar y tanbién des[de]q. el a[n]i[m]a. entiende las merçedes y benefiçios del señor la conmunycaçión que tienen co[n]. él no a de ser themerosa syno hazer como ester posponer los themores q. ally le pusyeren y confiarse y no dexar de entrar a pedir...

No basta el entendimiento, el obrar es producto de una acción voluntarista como es ese "mucho amar"; sin embargo, la acción pura de amar no es suficiente para buscar el amor religioso, el amor divino, pues para que ese impulso del vuelo espiritual surja debe conocerse sus beneficios, en ese instante ya no hay temor y, a partir de ahí: volar, entrar, pedir-orar. Francisca de Vera no se alinea ni con la defensa del intelecto llevada a cabo por la filosofia griega, ni con los postulados de la mística franciscana que antepone la voluntad, para primar así el amor, a la inteligencia -Francisco de Osuna afirmaba que la voluntad es la potencia más noble del hombre, (Ver, Místicos franciscanos españoles I. Madrid: BAC, 1948, p. 665)-, para Vera no parece que se pueda negar la participación de la inteligencia en la vida espiritual. No sigue tampoco a Occam y a Duns Scoto, franciscanos también, quienes en la polémica voluntad versus entendimiento preconizan la superioridad de la voluntad al primar la omnipotencia divina por encima de todo bien y todo mal. La Abadesa Vera incita a la oración como un acto voluntarista pero también intelectual: la voluntad es la "Reina ciega" que necesita ser alumbrada por la antorcha del entendimiento, es en ese momento cuando el vuelo espiritual del alma hacia el amado se hace perfecto, el alma-paloma-águila está compensada con las dos alas fundamentales: entendimiento y voluntad. Ahora sí se podrá volar.

30 Libro de Ester 7, 2: Ester pide al rey Asuero la vida de su pueblo. Francisca de Vera añade por su cuenta el acompañamiento de las dos doncellas; ambas son necesarias para su discurso como metáfora de las virtudes esenciales que debían adornar el alma voladora y, de paso, que debian tener sus novicias y monjas: dos doncellas que representan la misericordia y la mortificación. Vera tras ponderar la importancia de la oración, establece las virtudes con las que hay que afrontarla. 
del S. ${ }^{\text {or }}$ no a de entrar sin ser llamada pero como quyen quiere salbar la vida de su pueblo a de entrar co[n]. la petiçion de la or[aci]o[n]. y açercarse al señor adornada de las vyrtudes q. es el conoçim[ient]. ${ }^{\circ}$ de sy y de todas las de más q. hermo[sean el] a[n]i[m]a. y a de llebar vna donze / / IHS. lla en quien se recueste la qual le llebe de mano y ottra q. le llebe la falda, quién es la q. le lleba de la mano? La misericordia. quyén la de la falda? La mortificaçión. Y así a de entrar en la or[aci]o[n]. con esta conpañya porq. sy estas dos no lleba no le será dho lo q. a ester no por vos my h[e]r[man]. ${ }^{a}$ está puesta la ley. Y así quando la esposa del Señor y la Religiosa se vee estar desmayada y no se halla ally bien syno con vna sequedad q. a de hazer? Myrar si tiene donzella en quien se recueste. Si a hecho o dho. a alguna de sus $\mathrm{h}[\mathrm{e}] \mathrm{r}[\mathrm{man}] .^{\mathrm{a}} \mathrm{s}$ alguna cosa con q. la otra esté desgraçiada y con esta examinaçión bolv[er]. a la otra y echarse a sus pies y pedirle p[er]dón y quyetalla y consolarla y entonçes dirá el señor beati mysericordes y hará co[n]. el a[n]i[m]a. mysericordia consolandola y esforçandola en su desmayo. La otra donzella es la mortificaçión sin // IHS. la qual como sin la ottra no podemos agradar al Rey nro. [e]sposo. Esta mortificaçión en palabras, en trajes, en co[n] versaçiones, en cosas co[n]. dyscreçión q. pareçe q. nos da[n] gusto coger vn poco la falda no baya arasttrando y haga polvo al Rey. Esto es lo q. abemos de procurar mortificar n[osot]ras. hablas, n[uest] ros. tratos y conversaçiones cortar las sup[er]fluydades en todo p. ${ }^{\text {a }}$ q. podamos agradar a este Señor q. asy pasó su santísyma vyda tan mortificada por nosottros y tan llena de penitençia y entonces le llamará $\mathrm{h}[\mathrm{e}] \mathrm{r}[\mathrm{man}] .^{\mathrm{a}}$ mía y [e]sposa y le dará confiança q. ${ }^{\mathrm{e}}$ pida no solo p. $^{\text {a }}$ sy pero p. $^{\text {a }}$ ottros y salve la vyda de su pueblo. ${ }^{31}$

Y el a[n]i[m]a. tan faboreçida q. a de ordenar su buelo como la paloma a de ser dexadas las maliçias y astuçias de la serpiente y

31 Vera ha fijado hasta aquí el poder de intermediación para la salvación que la monja, el convento, como pontífice entre la inmanencia y la trascendencia, entre la Babilonia del cuerpo y la Nueva Jerusalén del alma, tiene en la sociedad. No es fácil llegar a conseguir ser una Ester capaz de pedir a su rey por sí misma y por su pueblo y ser oída por este, para lograrlo Francisca de Vera alude a esas virtudes entre las que destaca una que está en la tradición de la hermenéutica del Yo desde los griegos: el conocimiento de sí, el gnôthi seautón, el conócete a ti mismo délfico. (Ver GONZÁLEZ POLVILLO, Antonio, El gobierno de los otros. Confesión y control de la conciencia en la España moderna. Sevilla, Secretariado de Publicaciones de la Universidad de Sevilla, 2010, pp. 60-63). 
ser humylde y mansa y bolar adonde su [e]sposo le con // IHS. vida a los agujeros de la piedra y a lo hueco del valladar p. ${ }^{\mathrm{a}} \mathrm{q}$. ally gimiendo en la or[aci]o[n]. halle su descanso como dezia dabit en otra parte: my coraçón y mi carne se alegró en dios bibo ${ }^{32}$ donde dize q. ally halla el paxarito nydo y la tortolica que es el a[n]i[m]a. casta p. $^{a}$ ally poner sus pollytos. ${ }^{33}$ Ay algunos pu[n]tos por donde avemos de tener cosideraçión p. ${ }^{a}$ amar y conoçer al señor, vnos son por las criaturas considerando quien crió el çielo y la t[ie]rra. y los elementos y las aves y el ayre y todo lo criado y por aquy alabar al señor, ay otro modo negando q. es ver la grandeza del çielo y dezir esto no es mi dios y no como aquellos q. tenyan al sol y a ottros planetas por dioses. ${ }^{34}$ También vyendo la luz del sol la hermosura de todas las cosas como dyze santo agustin q. todas las cosas criadas nos dyzen no soy tu // IHS. ni dios p[er]..$^{\circ}$ él nos hizo. ${ }^{35}$ Tan

32 Salmo 16, 9: Se alegró por tanto mi corazón, y se gozó mi alma; mi carne también reposará confiadamente.

33 Salmo 84, 4: El pajarillo halló hueco donde guarecerse y nido la tórtola para poner sus polluelos. Tus altares, oh Señor de los ejércitos, oh rey mío y Dios mío. La famosa monja Hipólita de Rocabertí en su obra: La celestial Jerusalén. Valencia, 1683, glosará e interpretará este tema en el cap. ${ }^{\circ}$ XXXVII, p. 100: El gorrión halló para sí casa, y la tórtola nido donde poner sus pollitos..., significa la Santa Iglesia Romana, dentro la qual nos conviene obrar buenas obras, que significan los hijuelos (sigue a San Agustín); p. 101: Ya sabemos que la tórtola es ave gemibunda: assi por cierto lo ha de ser el alma del christiano, y q.e conozca muy de veras su triste cautividad, morando en la Babylonia de este mundo, y se tenga por peregrino, $y$ que suspire muchissimas vezes con San Pablo, diziendo: desdichado del hombre, o quién me librasse deste cuerpo de muerte! Codicio ser suelto y libre dél, y ver a Christo. O mi dulce Iesús, gimo de verme ausente de vos, suspiro muchas vezes de deseo de verme con vos: todo lo de acá tengo por estiercol para ganaros a vos: todo lo dexo, y olvido: vuestra viva memoria, y amor me haze dar gemidos inenarrables.

34 La Abadesa Vera, en su didactismo teológico para con sus novicias, ratifica el primer mandamiento de amar a Dios sobre todas las cosas. Sin embargo, traduce el rígido mandamiento al naturalismo monjil-conventual, por lo que ese amor se puede demostrar afirmando su grandeza y negando que haya algo más hermoso y sublime que el creador de todo. Reafirma también el monoteísmo de ese primer mandamiento, para lo cual rechaza las supersticiones idólatras planetarias en clara alusión a la astrologia judiciaria.

35 Francisca de Vera alude a San Agustín, seguramente cuando éste en la predicación interpela diciendo: "Interroga a la belleza de la tierra, interroga a la belleza del mar, interroga a la belleza del aire que se dilata y se difunde, interroga a la belleza del cielo [...] interroga a todas estas realidades. Todas te responden: Ve, nosotras somos bellas. Su belleza es su proclamación. Estas bellezas sujetas a cambio, ¿quién las ha hecho sino la Suma Belleza, no sujeta a cambio? Sermón 241, 2: PL 38, 1134. 
bien por la hermosura de las cosas p. $^{a}$ afiçionarnos quando vemos vn campo muy fermoso adornado de flores dezir q.é será ver a mi criador q. lo crió.

Quando veo vn ho[m]bre muy sabio y discreto y vyrtuoso dezir qué será la sabiduría de my señor Ihu Xpo y su fermosura. Y byendo vna mujer hermosa y onesta adornada de virtud conp[ar]ar q. será my señora la madre de dios q. no tubo par su p[er]fiçión? Y aquí es menester el entendim[ient]. ${ }^{\circ}$ tener criança a la Reyna çiega no se entremeta tanto en entender la figura q. se olbide de lo q. quyere q. q.[ue]de sellado. ${ }^{36}$

1.- Ottros puntos $\mathrm{p} .^{\mathrm{a}}$ consyderar son probechosos $\mathrm{p} .^{\mathrm{a}}$ la criatura co[n]fundirse en la presençia del señor en el prinçipio de la or[aci] $\mathrm{o}[\mathrm{n}]$. y son las q. se syguen: ${ }^{37}$

// IHS. quién era yo agora treynta o çinquenta años. Dónde estava my cabeça y mis $\mathrm{m}[\mathrm{an}] .^{\circ} \mathrm{s}$ y mys pies, q. serviçio hize yo a mi $\mathrm{S}[\mathrm{en}] .^{\text {or }}$ p. ${ }^{\mathrm{a}}$ q. me criase.

Q. le devo por aberme criado y criar çielos y t $[$ ie $]$ rra. p. $^{\mathrm{a}}$ mi y me costubyese y mantubiese y ayre $\mathrm{p}^{\mathrm{a}}{ }^{\mathrm{q}}$ que descansase y finalmente todo lo criado . $^{a}$ mi serviçio. Ya tiene aquí la nada q. es de su parte. ${ }^{38}$

2.- q. abia yo de hazer? Emplearme yo toda ynterior y esterior en serviçio del que tanto hizo por mí. My entendim[ent]. ${ }^{\circ}$, mi memoria,

36 La Abadesa Vera vuelve a aludir a las dos potencias del alma: entendimiento y voluntad, las dos alas del alma-paloma. Antes hemos visto cómo el entendimiento precede y alumbra con su antorcha a la voluntad en el conocimiento divino; ahora, en este oscuro pasaje, le advierte que no alumbre a la "Reyna ciega" en la comprensión de lo sellado, en los arcanos del misterio, el alumbramiento es intencionado y condicionado, impuesto a priori por una razón trascendente que se vehicula por la escolástica.

37 Parece que Vera propone a sus lectoras un programa de vuelo espiritual en cinco fases. Ahora bien, cada fase o propuesta no es propedéutica de la siguiente; la Abadesa preconiza así la voluntas y la libertas ofreciendo la posiblidad de elegir en función de los resultados.

38 En el ejercicio de ese conocimiento de sí al que antes aludía se llega a una verdad primaria: la nada del ser-ahí en la tierra. Es la humilitas, la monja que se dispone al vuelo espiritual parte de la negación de su ser inmanente, todo es trascendencia desde la posición inicial de ancilla. 
mi volu[n]tad, mys sentidos todo enteramente pagarle aquel tributo del alma y coraçón y las enttrañas que esta es la or[aci]o[n]. q. es de los mayores serbiçios y honra q. se le puede hazer, porq. aunq[ue]. de tres cosas abemos de hazer serviçio: de la hazienda dando lymos / /IHS. na, de n[uest]ro. cuerpo mortificandole y esto es agradable a nro. Señor, el tributo del alma y coraçón q. es la or[aci]o[n], este q. la criatura se reconoce ser nada y se humilla esto es agradable a su mag[estad]. ${ }^{39}$

3.- q. abía de hazer co[n]migo por mi yngratitud, ponerme en el ynfierno a los pies de judas adonde me atormentasen los demonyos, adonde vyese arder mys myenbros q. no enpleé en serviçio de mi criador.

4.- qué hizo? Darme vyda, darme medios.$^{a}$ mi bien, llamarme a penitençia, llamarme a mi coraçón $\mathrm{p}^{\mathrm{a}}{ }^{\mathrm{q}} \mathrm{q}$. le responda, y luego serán $\mathrm{p}[\mathrm{er}]$ didos los enojos sy yo p[er]diere los malos propósytos y proponga la enmyenda de la vyda y sobre todo darme los bienes que en mi S.or Ihu xpo nos dio criando su huma //IHS. nydad p. ${ }^{a}$ q. pagase por mí my deuda. Que fuese su cabeça lastimada por mi sobervia. Q. llorasen aquellos dibinos ojos por mi. Q. fuese aquel sacratissymo cuerpo atormentado por $\mathrm{mi} \mathrm{p}^{\mathrm{a}}$ rescatarme de mi deuda y ofreçer sacrifiçio agradable $\mathrm{p}^{\mathrm{a}}$ aplacar al padre por mí. ${ }^{40}$

39 Tras el agustiniano reconocimiento de la nada que se es, frente al inmenso hacedor de sublime belleza, Francisca de Vera se hace una pregunta que será recurrente en la tradición filosófica: ¿q[ué]. abía yo de hazer?-podemos recordar las célebres preguntas kantianas sobre el ¿cómo vivir?, y el ¿qué puedo hacer?-. La respuesta será ancilar, es decir, un axioma básico en la praxis vital no solo conventual sino de la sociedad moderna: pagar al señor, sea cual sea la condición de éste. Sin embargo, al Señor específico al que se dirige nuestra Abadesa, -que en la realidad cotidiana se objetiva en la razón trascendente impuesta por los señores sociales de los estamentos privilegiados-, nada le place más que cuando la criatura se reconoce ser nada y se humilla.

40 Pero ese hacedor de belleza, del que Vera se muestra deudora, no regala nada, exige el pago de la deuda. Envia a su hijo para pagar por los demás, su cuerpo fue atormentado por mi $p .^{a}$ rescatarme de la deuda. Pero este sacrificio, esta nueva inversión en deuda lo que hace es encarecerla. La Abadesa Vera vuelve a preguntarse en el siguiente punto ¿Qué hacer?. Una vez más la respuesta estará en el Antiguo Testamento con la figura de Acsa, hija de Caleb, metáfora, para Vera, del alma adornada por Dios, pero que llora por la tierra seca heredada, la herencia pecaminosa de los primeros padres, una deuda que solo por medio de la oración podrá ser atendida, pagada y permutada por las tierras de regadio, altas y bajas. Lágrimas y devoción: única manera de fertilizar la tierra del ser. 
5.- Consyderando esto, q. debo yo hazer?. Vime como salida y escapada del ynfierno myrar mis $\mathrm{m}[\mathrm{an}] .^{\circ} \mathrm{s}$ como ya no arden y mi cabeça como no está adonde tan bien lo merecía y dar gr[aci]as. al señor q. me escapó de aquellas penas p[er]petuas co[n]. vn p[ar]. ${ }^{a}$ syenpre no ay remedio y procurar cómo enmendar lo pasado pues escapé de lo que ymajyno syno haziendo vn firme propósyto de allegarme al vnyco remedio y hazer como hizo Axa hija de Calé q. se cuenta en la escriptura ${ }^{41}$ q. su pa // IHS. padre abya repartido las $\mathrm{t}[i e]$ rras. y cupole las más secas y desyertas y tomó por remedio yren vn jume[n]to y ally sospirar y pregutandole el padre porq. sospiraba le dixo: padre dame tu bendiçión y dame el regadio alto y el baxo pues me as dado la t[ie]rra. seca y sin fructo, y el padre asi se lo conçedió. Quién es Axa sino el a[n]i[m]a. adornada de dios q. esto quyere dezir la adornada pues le adornó criandole a su ymajen y semejança adornandole de las virtudes y bestidura de ynoçençia. La qual como se vee por su descuydo aver p[er]dido llora y sospira la triste erençia q. le cayó de su padre Adán q. es la t[ie] rra. seca y quemada q. no puede por si dar buen fruto. Toma por remedio sentarse sobre su asnyllo, esto //IHS. es sobre su carne subjetandola y mortificandola y señoreandola y entonçes sospirar a su señor y padre q. es dios y entonces le dirá q. quyeres hija? Y dirá: señor q. ${ }^{e}$ deys v[uest]ra. bendiçión y pues me cupo tan mala t[ie]rra. $\tan$ seca y $\tan$ q[ue]mada por las tentaçiones y tribulaçiones de la carne, dame el regadio alto y el baxo, esto es, lágrimas y devoçión p. ${ }^{\text {a }}$ q. esta t[ie]rra. tan q[ue]mada co[n]. el alto regadio pueda dar buen fruto y q. piensa q. negará el q. tiene dada palabra y que nos ynpide pues tal prenda tenemos pues dize en verdad en verdad $\mathrm{q}$. qualquyer cosa q. pidiere al padre en mi no[m]bre os será dada.

41 Libro de Josué, 15: Territorios que tocaron en suerte a la tribu de Judá y sus ciudades. Josué se apoderó de Hebrón y de todas sus dependencias. Otoniel se casa con Acsa hija de Caleb por haber conquistado aQuiriat-sefer. En 15, 15: Y subiendo desde alli llegó a los habitadores de Debir, que antes se llamaba Quiriat-sefer, esto es, ciudad de letras. En 15, 16: Y dixo Caleb: Al que hiriere aQuiriat-sefer, y se apoderare de ella, le daré a Acsa mi hija por muger. En 15, 17: Y tomola Otoniel hijo de Cenaz hermano menor de Caleb: y dióle por mujer a Acsa su hija. En 15, 18: La qual, quando iban todo de compañia, fue aconsejada por su marido que pidiera a su padre un campo, y así como iba sentada en su asno, dio un suspiro. $Y$ Caleb la dixo: ¿Qué tienes? En 15, 19: Y ella respondió: Dame tu bendición: me has dado una tierra de secano hacia el medidodia, agrégame otra de regadio. Y Caleb le dio una tierra que se regaba por la parte de arriba y de abajo. 
Tambyen se a de co[n]syderar q. destos pu[n]tos no todos an de co[n]syderar juntos //IHS. juntos syno como haze el pobre q. demanda de puerta en puerta y si le dyzen: Dios os ayude, vase a ottra y a ottra y quando syente alguna señal q. no le respo[n]de[n] $\mathrm{p}[\mathrm{er}] .^{\circ}$ meneanse y abren el arca espera a aquella puerta. Asy a de hazer el a[n]i[m]a. yrse de punto en pu[n]to y si en el vno o en el ottro no le dan lymosna y le despiden y no le reçiben vase a ottro y des[de] q. syente q. abren el arca y se menean q. es señal q. no le despiden y es quando el pu[n]to le da enttrada y halla lugar y qyetud estese ally esperando q. asy le darán consuelo, amen. ${ }^{42}$

\section{CONCLUSIÓN}

Observamos que la Madre Francisca de Vera, Abadesa durante treinta años del Convento de la Concepción de la villa de Lebrija, se encuentra inserta en un movimiento genealógico espiritual que arranca desde la primera mitad del siglo XVI y llega hasta un siglo después, al tiempo que practica y transmite una espiritualidad muy especial con claras connotaciones evangélicas, visionarias, proféticas, milenaristas que, en gran medida, se inscriben en la tradición de reformatio ecclesiae y de esperanza en la aceleración de la Historia que encontramos en Europa desde el siglo XII y, más concretamente, con la irrupción de las ideas milenaristas y de división trinitaria de la Historia del abad calabrés Joaquín de Fiore que, sin duda, quebró el pesimismo agustiniano instalado en la cristiandad. Aunque, eso sí, con la aportación novedosa y extraordinaria de la definición del dogma de la Inmaculada como momento de fijación de la Parusía. En este movimiento la Abadesa de Lebrija juega un papel muy importante y especial, así como su

42 En el interior de la cubierta trasera, tal vez de la misma letra pero escrita en otro momento: a quanto peligro les hayga y por el contrario quanto les importa el bien asconderse y guardarse para que las flores que an produzido ques señal de que presto darán el fruto deseado, den su olor, el qual olor ahuyenta las serpientes y todo animal ponçoñoso se aparta deste lugar y nunca pueden çufrir el olor destas nueuas flores. Aduiertan asimismo las nouitias que tal es el spíritu que an reçebido del señor pues las primitias del no pueden çufrir los demoni[os] y si tal es y tanto pueda el feruor de las nouitias qué será deso considera la uida de perfection consumadas. 
propio convento el cual se convertirá en convento-reliquia de esta "nueva religión de los Crucíferos" tal como los había denominado en su profetismo San Francisco de Paula: alli profesarán de monjas las hijas de muchos miembros de la Congregación de la Granada sevillanos; allí terminarán enterrados, por traslado desde Jerez y Sevilla respectivamente, los huesos de Gómez Camacho y Rodrigo Álvarez, que serán venerados por las monjas como auténticos santos; allí se venerarán como reliquias los huesos, y sobre todo la calavera, aún existente, de Francisca de Vera con la que se realizarán muchos milagros; y allí se enviarán por orden del último cabeza de la Congregación de la Granada, Bernardo de Toro, cuando realice en Roma su testamento en 1641, las últimas reliquias de la Congregación: ${ }^{43}$

Mando que si se diesse el caso de mi muerte antes de llegar yo a Sevilla mis albazeas estén advertidos de ynbiar y remitir al dicho conbento de monjas de Lebrija luego que llegare a sus manos vn Santo Crucifixo de latón o bronze dorado en cruz de ébano de vn palmo de alto que conmigo e traydo y que fue del benerable padre de la Compañía Rodrigo Álbarez, y ansimismo vna cruz pequeña de madera engastada en plata que siempre e traydo a el cuello la que fue del venerable padre y señor Gómes Camacho a quien la dio el señor arçobispo de Sevilla don Fernando de Valdes ynquisidor general por los años de mil y quinientos y cinquenta e era la que traya a el cuello quando le esaminó su espíritu que ambas piesas tienen ynnumerables yndulgencias, enviese a dicho convento de Lebrija con esta cláusula de testamento.

43 GONZÁlEZ POLVILLO, Antonio, Inquisidores, dominicos y alumbrados, ob. cit., pp. 137-142. Sobre los orígenes y motivaciones del regalo del inquisidor general puede verse GONZÁLEZ POLVILLO, Antonio, El jesuita y confesor de Santa Teresa, ob. cit., pp. 147-153. 
LA MADRE FRANCISCA DE VERA (1514-1574), ABADESA DEL CONVENTO DE LA CONCEPCIÓN DE LEBRIJA, Y SU TRATADO DE LA ORACIÓN

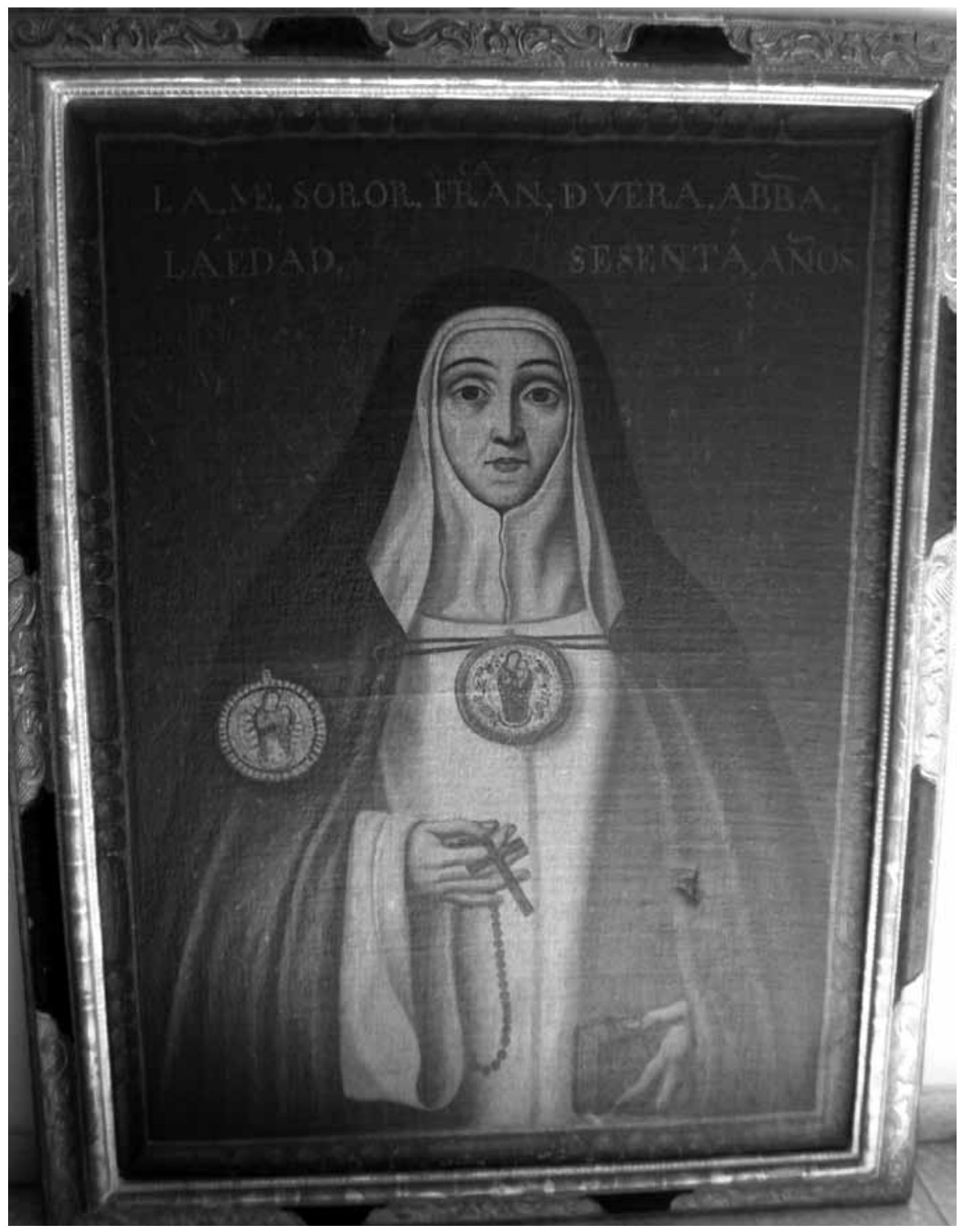

Retrato de la Madre Abadesa Francisca de Vera. Óleo sobre lienzo. S. XVII. Convento de la Inmaculada Concepción de Lebrija. 


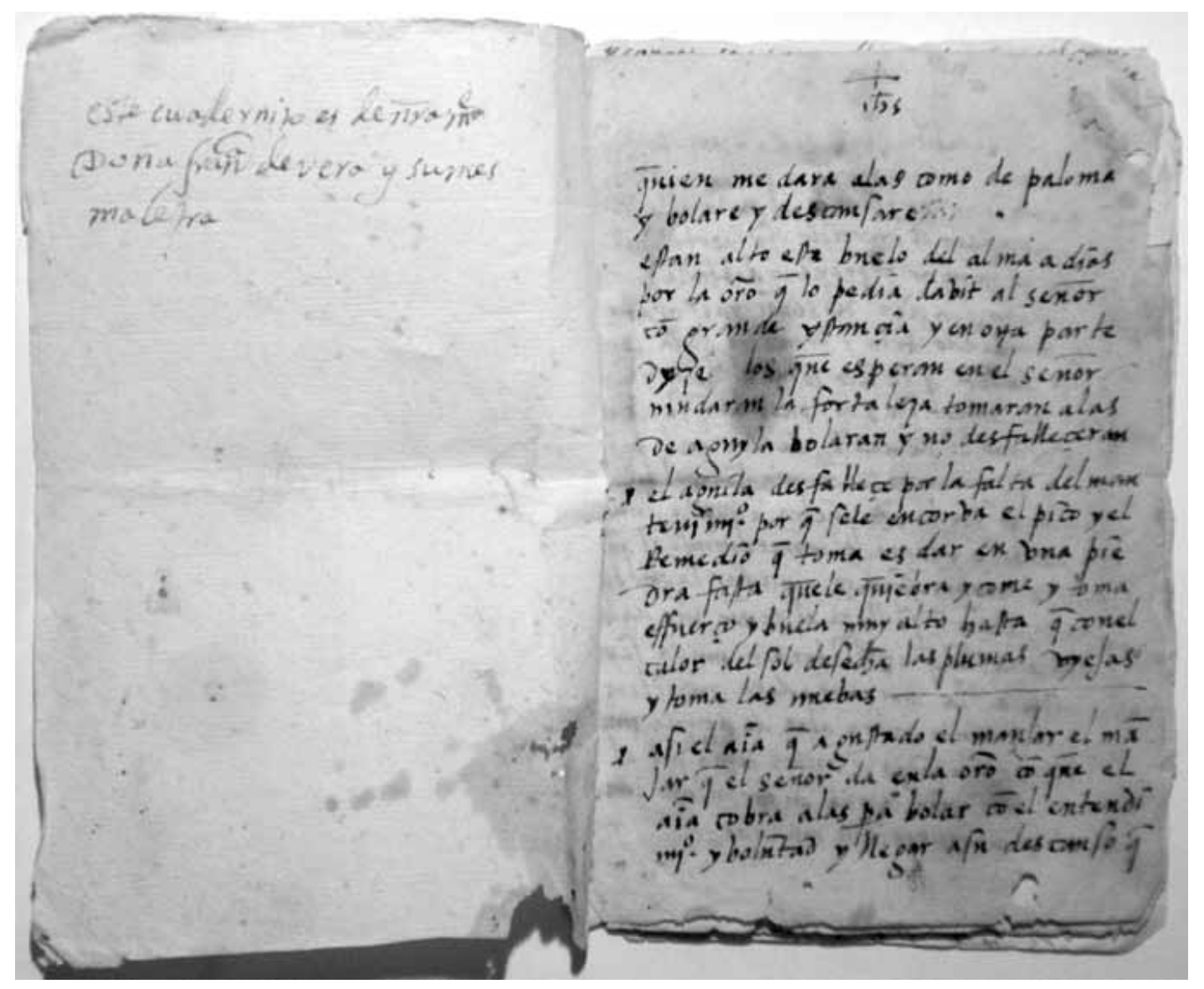

Tratado de Oración. S. XVI. Original de la Madre Francisca de Vera. Convento de la Inmaculada Concepción de Lebrija. 
LA MADRE FRANCISCA DE VERA (1514-1574), ABADESA DEL CONVENTO DE LA CONCEPCIÓN DE LEBRIJA, Y SU TRATADO DE LA ORACIÓN

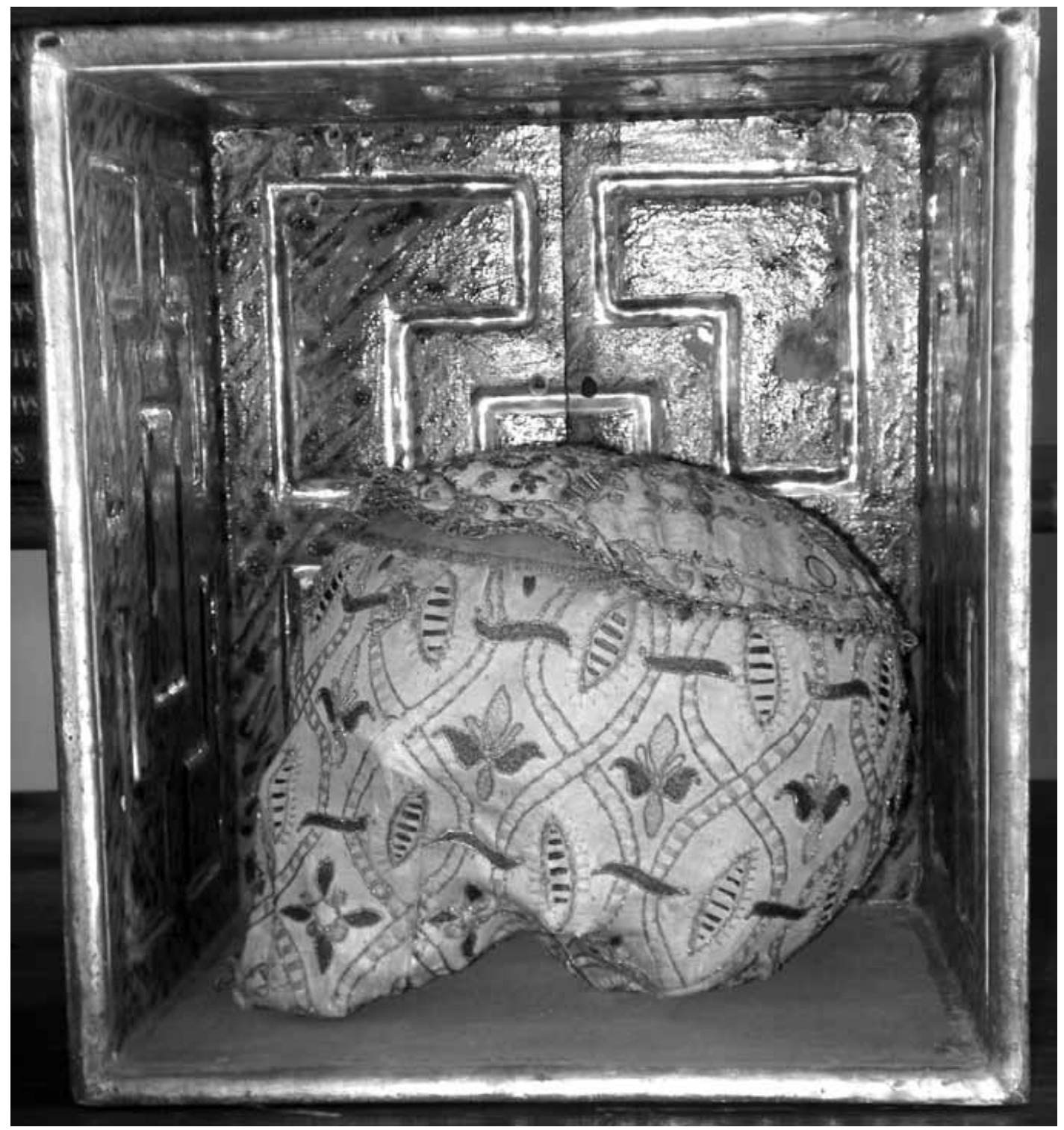

Calavera de la Madre Abadesa Francisca de Vera (1514-1574), venerada en el Convento de la Inmaculada Concepción de Lebrija. 